\title{
POLÍTICAS DE TRANSPORTE MOTORIZADO NO BRASIL E SEUS REFLEXOS SOBRE A AMAZÔNIA LEGAL
}

\author{
Isabela Soares Colares \\ Universidade Federal do Amazonas - UFAM. \\ isabelacolaressoares@gmail.com \\ Geraldo Alves de Souza \\ Universidade Federal do Amazonas - UFAM \\ geraldoalves@ufam.edu.br
}

\begin{abstract}
RESUMO
Esta pesquisa tem como objetivo analisar os reflexos das políticas de transporte adotadas no Brasil sobre a motorização e os registros de óbitos por Acidentes de Transporte Terrestre (ATT) na Amazônia Legal. Para isso utilizou-se os registros de óbitos do Sistema de Informação de Mortalidade (SIM), disponibilizados por meio do Departamento de Informática do Sistema Único de Saúde (DATASUS) e de frota de veículos do Registro Nacional de Veículos Automotores (RENAVAM). Constatou-se que as motocicletas participam com aproximadamente $48 \%$ na composição da frota de veículos da Amazônia Legal e são responsáveis mais de $43 \%$ dos óbitos por ATT da região. Verificou-se também que estes números não param de crescer desde que políticas de incentivos à aquisição destes veículos passaram a ser adotadas e o transporte de passageiros por mototáxi foi admitido nas cidades da região.
\end{abstract}

Palavras-chave: Políticas. Transporte Motorizado. Óbitos.

\section{MOTORISED TRANSPORT POLICIES IN BRAZIL AND ITS REFLECTIONS ON THE LEGAL AMAZON}

\begin{abstract}
This paper aims to discuss the reflection on the transport policies adopted in Brazil on the motorization and the records of deaths due to land transport accidents in the Amazônia Legal. For that, we used the death records of the Mortality Information System (SIM), made available through the Department of Informatics of the Unified Health System (DATASUS) and the vehicle fleet of the National Motor Vehicle Registry (RENAVAM). The vehicle fleet is from the Registro Nacional de Veículos Motores (RENAVAM). There is verified evidence through the data that that the policies of incentive to the individual transports, mainly of the motorcycle reflect in the composition of the vehicle fleet of the Legal Amazon where $48 \%$ is due to the size of the vehicles and the number of fatalities due to land transport accidents represent more than $43 \%$ of the statistics. These numbers have increased since this vehicle began to be stimulated and used as means of transport.
\end{abstract}

Keywords: Politics. Motorized Transport. Deaths.

\section{INTRODUÇÃO}

Desde meados do século passado o padrão de mobilidade da população urbana brasileira vem passando por fortes modificações, reflexo principalmente do intenso e acelerado processo de urbanização ocorrido no país neste período, do crescimento da frota de veículos automotores e das viagens urbanas por modos motorizados de transporte.

As políticas de estímulo aos transportes individuais motorizados, associadas ao encarecimento do transporte público coletivo, resultaram no aumento da frota de automóveis e motocicletas nas cidades brasileiras. Este crescimento da motorização resultou no agravamento dos problemas de mobilidade, tais como: aumento dos congestionamentos, da poluição, da exclusão social e dos acidentes de trânsito. Esse último é considerado como a maior externalidade produzida pelos transportes no Brasil, responsável pelo elevado número de vítimas e diversas implicações para a sociedade.

Com informações sobre mortalidade no trânsito em 180 países, o relatório "Situação Global sobre Segurança Rodoviária em 2015", da Organização Mundial da Saúde (OMS), aponta que são registradas 
1,25 milhão de mortes por ano no trânsito no mundo. Entre as quais, 31\% são ocupantes de automóveis, $23 \%$ são motociclistas, $22 \%$ são pedestres e $4 \%$ são ciclistas (WHO, 2016). No Brasil, em decorrência dos acidentes de trânsito em dez anos (2003-2012), a taxa de mortalidade nas vias passou de 18,7 para 23,4 para cada 100 mil habitantes. Este índice se aproxima do registrado nos países africanos, sendo estes considerados os mais letais no trânsito, com média de 26,6 (WHO, 2016).

Segundo Leite et al. (2015), com o aumento da população e a consequente ampliação do espaço urbano, reduziu-se os deslocamentos realizados a pé devido ao aumento das distâncias, implicando na adoção de modos motorizados de transporte. As cidades da Amazônia Legal - (AL) estão inseridas nessa realidade. Aqui o transporte motorizado apresentou um grande crescimento, impulsionado pelo acesso fácil ao crédito, principalmente para a aquisição de motocicletas. Os dados do Departamento Nacional de Trânsito - (DENATRAN) apontam que a frota circulante da Amazônia Legal mais que dobrou no período de 2001 a 2015, passando de 3,5 para 8 milhões de veículos; um aumento de mais de $228 \%$. Os veículos de duas rodas saltaram de 500 mil em 2001 para 4 milhões em 2015; uma taxa de crescimento de $800 \%$ no período, bem superior crescimento dos automóveis.

Os óbitos causados por automóveis duplicaram de 2001 para 2015, passando de pouco mais de 3.248 para 6.217 e as internações subiram de 17.755 para 35.763 vítimas no mesmo período. Nesse sentido, faz-se necessário compreender melhor a realidade da motorização, dos acidentes de trânsito na Amazônia Legal e entender como as políticas de transporte do Brasil repercutem sobre o perfil da motorização nessa região, mesmo em cidades sem ligações rodoviárias com outros municípios realidade de boa parte dos municípios da Amazônia central. Dessa forma, esta pesquisa tem como objetivo analisar os reflexos das políticas de transporte adotadas no Brasil sobre a motorização e os registros de óbitos por ATT na região. Com os resultados da pesquisa foram elaboradas ilustrações gráficas em um Sistema de Informações Geográficas - SIG e em planilhas eletrônicas.

A fonte dos dados de óbitos do período de 1996 à 2013 foi a base nacional do Sistema de Informação de Mortalidade (SIM), disponibilizada pelo departamento de informática do Sistema Único de Saúde (DATASUS), que compila as estatísticas de óbitos partir da documentação das pessoas atendidas nos estabelecimentos da rede pública de saúde. Os dados da frota de veículos são do ano de 2013 do Registro Nacional de Veículos Automotores (RENAVAM) do DENATRAN e os dados da população residente são do Censo demográfico de 2010 do Instituto Brasileiro de Geografia e Estatística - (IBGE).

\section{CONSIDERAÇÕES SOBRE AS POLÍTICAS DE TRANSPORTE MOTORIZADO NO BRASIL}

A industrialização no Brasil teve como reflexo o aumento da migração do campo para as cidades. Essa entrada de pessoas em ambientes urbanos induziu o aumento das dimensões das cidades, impulsionando a demanda por de transporte motorizado. Concomitante a este processo, a indústria automobilística representou o início da oferta regular de transporte individual que passou a disputar com o transporte público, tornando-se uma fonte crescente de receitas de impostos para a economia do país (VASCONCELLOS, 2013).

Ao falar sobre os sistemas de transporte no Brasil, dois processos simultâneos devem ser destacados: a crescente urbanização após a $2^{\mathrm{a}}$ Guerra Mundial e a implantação da indústria automotiva a partir de 1956 (VASCONCELLOS e MENDONÇA, 2010; VASCONCELLOS, 2013). Estes, de maneira geral, contribuíram para a motorização da sociedade brasileira, seja com o uso de ônibus, seja com o uso de automóveis particulares e, mais recentemente, o aumento da participação das motocicletas.

O início da promoção de políticas de estímulo à indústria automobilística no país pode ser creditado ao governo de Juscelino Kubitschek (JK). Dentre suas principais ações, está a criação do Grupo Executivo da Indústria Automobilística (GEIA), em 1956, para estudar, planejar e aprovar projetos nesta área e implantar a indústria automobilística. Vale destacar que antes do governo JK, os veículos motorizados já circulavam nas cidades brasileiras, conforme enfatizado por Caputo e Melo (2009, p. 518):

Antes do governo de Kubitschek, não se fabricava veículos no Brasil - eram apenas montados com peças importadas. Algumas autopeças eram fabricadas, mas o processo como um todo não era possível no país. As principais investidoras do setor foram a General Motors Corporation e a Ford Motor do Brasil S/A, ambas americanas (CAPUTO e MELO, 2009, p. 518).

Segundo Latini (2007), em 1900 no Brasil havia apenas quatro automóveis importados. Em 1920, já eram cerca de 30 mil veículos, entre automóveis e caminhões e em 1940 existiam mais 160 mil, um aumento de mais de $500 \%$ em vinte anos (LATINI, 2007). A partir da entrada da indústria automobilística, o número de 
veículos cresceu rapidamente. A tabela 1 mostra o crescimento da produção interna, sem considerar a produção de motocicletas.

Tabela 1 - Brasil - Produção de Veículos de 1957-2015

\begin{tabular}{rrrrrrr}
\hline Ano & \multicolumn{1}{c}{ Automóveis } & Comerciais Leves & Caminhões & Ônibus & \multicolumn{1}{c}{ Total } \\
\hline 1957 & 10.449 & 1.588 & 16.259 & 2.246 & 30.542 \\
1960 & 70.479 & 20.875 & 37.810 & 3.877 & 133.041 \\
1970 & 319.574 & 54.069 & 38.388 & 4.058 & 416.089 \\
1980 & 873.721 & 105.572 & 97.463 & 14.449 & 1.091 .205 \\
1990 & 604.499 & 177.749 & 48.219 & 12.962 & 843.429 \\
2000 & 1.298 .437 & 214.994 & 71.114 & 21.303 & 1.605 .848 \\
2010 & 2.682 .924 & 468.747 & 189.941 & 40.531 & 3.382 .143 \\
2015 & 2.017 .639 & 316.222 & 74.062 & 21.498 & 2.429 .421 \\
\hline
\end{tabular}

Fonte: ANFAVEA, 2016.

Os dados destacam que a produção anual mais acelerada foi dos automóveis, saltando de 10.449 , em 1957, para mais de 2 milhões em 2015, um aumento de quase vinte mil por cento no período. A esta produção pode ser somada a dos veículos comerciais leves (caminhonetes, kombis, vans), cujos usos são muito próximos daqueles. A opção que o Brasil fez pelo transporte rodoviário serviu de estímulo ao uso de caminhões e ônibus para o transporte de cargas e passageiros, impulsionando a produção do setor. Já os comerciais leves apresentaram maior crescimento no período, fechando o ano de 2015 com 316 mil unidades fabricadas. A partir dos anos 2000 , a produção de automóveis passou a corresponder à aproximadamente $70 \%$ de toda a produção, mantendo-se nos anos seguintes. Faz-se necessário destacar que parte da produção nacional destina-se ao mercado externo, ao mesmo tempo em que veículos produzidos em outros países são importados para circular no Brasil.

Com a entrada no país das grandes multinacionais da indústria automobilística, os veículos de transporte individual foram sendo adquiridos por grupos sociais de renda média e alta, tornando-se fator pressão sobre políticas públicas e importante fonte de geração de empregos e impostos (VASCONCELLOS e MENDONÇA, 2010). Contudo, nas décadas de 1990 e 2000 o governo federal passou a atuar de maneira decisiva no incentivo à aquisição de veículos de uso individual, tratado como importante fator econômico e gerador de empregos. Dentre as principais ações, cabe destacar reduções tributárias concedidas em 1993 aos modelos de veículos mais popular e a contenção dos preços dos combustíveis através da criação da Contribuição de Intervenção no Domínio Econômico (CIDE) na área dos combustíveis (Vasconcellos, 2013). Algumas das medidas diretas e indiretas voltadas para o incentivo ao uso do automóvel são assim analisadas por Vasconcellos:

As medidas diretas estão relacionadas com o apoio à indústria automobilística, a facilitação da compra do automóvel e a criação de infraestrutura viária adaptada ao seu uso. As medidas indiretas se referem à liberdade irrestrita de circulação e quantidade de estacionamento nas vias públicas, a cobrança de custos irrisórios de licenciamento anual e a deficiência estrutural de fiscalização do comportamento dos condutores e dos veículos (2013, p.38).

Do ponto de vista da infraestrutura, a construção de um sistema viário extenso responde às necessidades de uso para o transporte individual, com facilidade de acesso aos diferentes lugares das cidades. Em contrapartida, há uma marginalização do sistema de transporte público, no qual as pessoas ficam limitadas às linhas de ônibus, à baixa frequência de passagem e a espera em paradas sem infraestrutura adequada.

A redução do custo médio do produto, a partir dos anos 1961 a 1987, e a criação do carro 1.0 mostraramse como medidas para popularização deste, impactando diretamente no patamar de vendas.

O barateamento do veículo 1.0 elevou as vendas da indústria de 600 mil unidades em 1992 para 1,5 milhão em 1997. Essa mudança no patamar de vendas representou a decisão mais importante de apoio à motorização privada no Brasil, que coincidiu com o declínio acentuado do uso do transporte público (VASCONCELLOS, 2013, p. 40).

Ainda sobre esta política, Vasconcellos et al. (2011) destacam que no ano de 1993 foi implantada a ação mais determinante para a consolidação do automóvel no Brasil: o Imposto sobre Produtos Industrializados (IPI), do carro de mil cilindradas foi reduzido de 20 para $0,1 \%$. Sua produção aumentou continuadamente, 
a ponto de transformá-lo em líder de vendas a partir de 1997, atingiu o pico de participação de $71,7 \%$, em 2001. O Instituto de Pesquisa Econômica Aplicada (IPEA) detalha a questão:

Nos últimos anos, os automóveis têm desfrutado de subsídios diretos concedidos pelos governos federal e locais. [...] merece destaque a redução pelo governo federal da alíquota do Imposto sobre Produtos Industrializados (IPI) para a aquisição de veículos novos de baixa cilindrada, a maioria do mercado nacional [...] considerando uma base de tributação do IPI de $25 \%$, estimou-se em cerca de R $\$ 7$ bilhões os subsídios recebidos pela indústria automobilística em 2004 referentes a esse item. Considerando uma base de $13 \%$ (veículos entre 1.000 cc e 2000 cc), o subsídio seria de $R \$ 1,5$ bilhão (IPEA, 2011, p. 4).

Simultaneamente à redução do IPI e a redução do custo, destacam-se as formas de financiamento e consórcio. "O crédito para a compra de automóvel foi formalizado em 1959 pelo governo, que passou a definir o prazo do financiamento, os juros a serem cobrados e a parcela do valor de compra que podia ser financiado" (VASCONCELLOS, 2013, p. 44). O incentivo do governo à indústria automobilística é ressaltado pela Associação Nacional de Fabricantes de Veículos Automotivos (ANFAVEA), que aponta a influência nas decisões governamentais sobre a construção, a aquisição e o uso dos automóveis, bem como a implantação da indústria automobilística no Brasil.

Nos primórdios, para estimular a produção nacional, o governo concedeu alguns benefícios, como taxas de câmbio mais favoráveis apenas para a importação de peças não fabricadas localmente e crédito para o financiamento de máquinas e equipamentos destinados à instalação e ampliação do parque fabril brasileiro. Passada a fase de implantação, o setor automotivo cresceu a taxas médias de $20 \%$ ao ano, no período de 1967 a 1974. Tal incremento só foi possível porque o governo, nessa ocasião criou mecanismos de crédito para o consumidor adquirir veículos (ANFAVEA, 2006, p. 23).

Do ponto de vista do uso e manutenção do automóvel nas vias públicas, Vasconcellos (2013) assinala que, em termos de rigor de controle público sobre a manutenção adequada dos veículos, esta é considerada baixíssima, embora o Código de Trânsito Brasileiro (CTB) de 1997 apresente regras e obrigações pontuais com relação à manutenção dos veículos.

A partir de 1990, os esforços também passam a ser voltados para a liberação da motocicleta como meio de transporte individual, com preços acessíveis à população de baixa renda, tornando a aquisição desse tipo de veículo uma importante estratégia para os deslocamentos diários, tanto em cidades menores quanto nas metrópoles e na zona rural. Nos anos 2000, nota-se que o governo federal continua canalizando seus esforços para a motorização individual no país por meio de desonerações fiscais e pela oferta de veículos mais baratos

As motocicletas não eram economicamente relevantes no Brasil; usadas em sua maioria para o lazer. Num contexto de mudanças na economia global e a convivência com forças poderosas de desregulamentação e privatização, "as políticas federais começaram a apoiar a massificação desta nova tecnologia, que passou a ser utilizada na entrega de documentos e pequenas mercadorias nas grandes cidades" (VASCONCELLOS, 2013, p. 81). Conforme destaca esse autor,

No Brasil a motocicleta era, até o final da década de 1980, um veículo de cunho esportivo, limitado a um grupo pequeno de pessoas da elite ou da classe média. A partir de então, as vendas internas passaram a crescer exponencialmente, de 123 mil unidades em 1990, para 1 milhão, em 2005, atingindo mais de 2 milhões, em 2011, um valor próximo ao da venda de automóveis (VASCONCELLOS, 2012, p. 30).

Com os incentivos fiscais e o apoio político do governo federal, a indústria motociclista abriu um novo ramo de negócios, dado principalmente pela liberação da importação em 1991, com os benefícios fiscais para a produção de motocicletas e facilidade de compra proporcionada pela autorização de consórcios e vendas financiadas a longo prazo, estimulando o aumento da produção. A tabela 2 mostra que em 1975 a produção foi de apenas 5.220 unidades e em cinco anos passou de 125 mil unidades, fechando o ano de $2015 \mathrm{com}$ mais de 1,2 milhão de motocicletas produzidas, um crescimento de mais de novecentos porcento no período de 35 anos (ABRACICLO, 2015). A tabela 2 mostra esta evolução. 
Tabela 2 - Brasil - Produção de Motocicletas de 1975 - 2015

\begin{tabular}{c|c}
\hline Ano & Produção de Motocicletas \\
\hline 1975 & 5.220 \\
1980 & 125.000 \\
1985 & 161.378 \\
1990 & 146.735 \\
1995 & 217.327 \\
2000 & 634.984 \\
2005 & 1.213 .517 \\
2010 & 1.830 .614 \\
2015 & 1.262 .708 \\
\hline \multicolumn{2}{|c}{ Fonte: ABRACICLO, 2015 }
\end{tabular}

A aceitação da motocicleta como meio de transporte foi tão grande que ela saiu das garagens e lazer dos finais de semana para a ocupação das ruas no cotidiano de todas as cidades do Brasil, com uso voltado para os deslocamentos diários. Para Vasconcellos (2013, p. 9), "as políticas construíram as condições baseadas em benefícios e isenções dadas aos automóveis e às motocicletas e em políticas inadequadas de oferta e circulação do transporte coletivo que aumentaram seus custos e diminuíram sua confiabilidade". Reflexo desses processos de incentivo ao transporte individual (motocicletas e automóveis) é a atual composição da frota de veículos no Brasil, com mais da metade constituída por automóveis, $57 \%$, conforme mostrado na figura 1 . Em seguida, aparecem as motocicletas, com $23 \%$, caminhonetes $8 \%$. Os ônibus e micro-ônibus aparecem com percentuais abaixo de $1 \%$, com frota de 590.657 e 375.274 , respectivamente.

Figura 1 - Composição da frota de veículos no Brasil em 2015

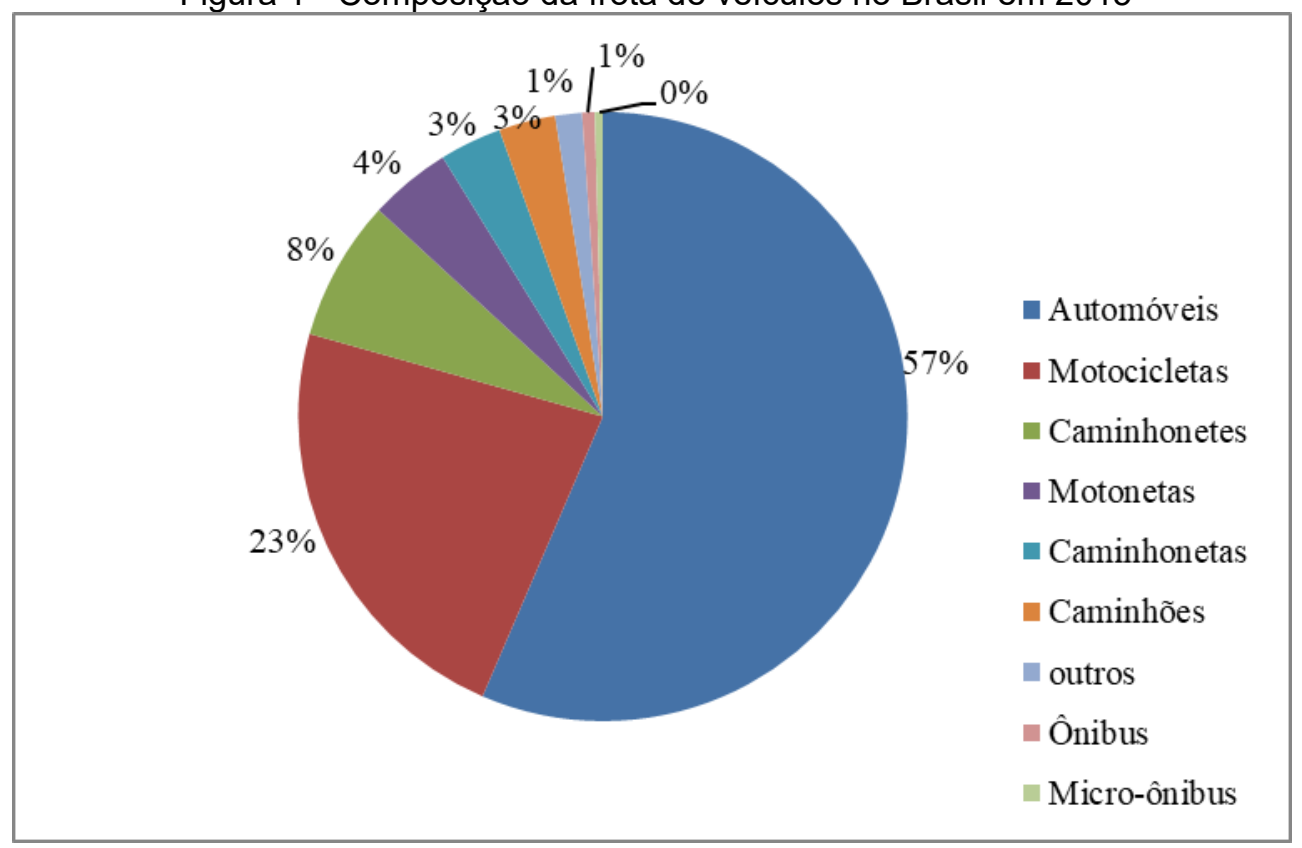

Fonte: DENATRAN, 2015

Em se tratando de frota de veículos, a combinação dos incentivos já citados e a oferta regular de veículos individuais resultaram num aumento da motorização privada no Brasil. De acordo com o Observatório das Metrópoles (2015), desde 2001, foram acrescidos à frota um total de 32,3 milhões de automóveis. Com isso, o país terminou 2014 com um total superior a 56,9 milhões. A taxa de motorização passou de 14,4 automóveis para cada 100 habitantes em 2001 para 28,1 em 2014. Aumento de praticamente $100 \%$ em 13 anos. Já em relação à frota de motocicleta, a taxa de motorização passou de 2,7 motos por 100 habitantes em 2001 para 11,3 em 2014, aumento de 418\% no período (OBSERVATÓRIO DAS METRÓPOLES, 2015).

Por outro lado, o transporte por ônibus veio acompanhado de uma precariedade que ajudaram a alimentar a visão crescente do transporte coletivo como uso para pessoas de segunda classe e para quem ainda 
não conseguiu seu automóvel. Segundo o IPEA (2011), entre 1977 e 2005, houve uma queda no uso do transporte público de $68 \%$ para $51 \%$ e aumento no uso do automóvel de $32 \%$ para $49 \%$, nas grandes cidades brasileiras. As condições de circulação e de qualidade dos ônibus também contribuem para o seu descrédito:

As condições de conforto dos ônibus brasileiros sempre foram precárias. Isso esteve relacionado ao padrão construtivo dos veículos e ao nível de vibração e ruído por eles produzido, assim como os assentos para acomodação das pessoas. A superlotação dos veículos, especialmente nas periferias é um fato que se representa há décadas e que muito contribuiu para o seu descrédito (VASCONCELLOS, 2013, p. 111).

Vasconcellos e Mendonça (2010) apontam que até o início da década de 1990, o uso do ônibus urbano cresceu na proporção da população. A partir de 1990 e até o ano 2000, ocorreu uma redução no uso de ônibus urbanos em comparação com a população do país. Em relação à demanda, caiu de 443 para 329 milhões de passageiros por dia entre 1994 e 2010.

Ao considerar este cenário de tendências à queda do uso do transporte público coletivo e o aumento do individual, Vasconcellos e Mendonça (2010, p. 74) destacam que os resultados estão diretamente relacionados com a saída do governo federal do tema, pela extinção da Empresa Brasileira de Transportes Urbanos (EBTU). Outro motivo está relacionado com o modelo de regulação, "se por um lado a regulamentação permitiu a profissionalização do serviço, por outro lado deu aos operadores condições legais de resistirem às suas formas de operações" (VASCONCELLOS, 2013, p. 53). De acordo com este autor a regulamente do transporte público no Brasil possibilitou:

à criação de um setor empresarial amplo que passou a adotar procedimentos de organização administrativa e operacional mais compatíveis com a natureza de uma empresa [...] No entanto, as formas de regulamentação, as características da demanda e a fragilidade do estado permitiram uma grande concentração de propriedade [...] que permitiram a formação de monopólios geográficos, protegidos por contratos de longo prazo, com cláusulas de garantia de equilíbrio econômico-financeiro (VASCONCELLOS, 2013, p. 78).

O resultado dessas políticas é o abandono do transporte público e o aumento da motorização individual no Brasil, que, segundo Vasconcellos (2013), consolidou-se a partir dos anos 2000. Uma das consequências desse processo é o aumento da geração de vítimas por acidentes de trânsito.

Vasconcellos (2012) destaca que uma das características dos acidentes de trânsito no Brasil, assim como nos países em desenvolvimento é que as vítimas mais vulneráveis, como pedestre e ciclista são também as mais fatais. Nesses países, de $50 \%$ a $60 \%$ das vítimas são pedestres, enquanto nos países desenvolvidos os registros são de $25 \%$. Nesse sentido, essa comparação mostra o uso irresponsável dos veículos motorizados, "na medida em que uma minoria conduzindo veículos impõe perdas sociais e econômicas enormes à maioria que anda a pé ou de bicicleta" (VASCONCELLOS, 2012, p. 110).

Ao analisar o processo de motorização e seus impactos sobre os números de acidentes de trânsito no Brasil, Vasconcellos (2016) aponta a existência de duas "fases selvagens". A primeira está relacionada à apropriação do nosso espaço viário por grupos selecionados, com acesso ao automóvel e com poder de pressão sobre o setor público e a segunda inicia-se em 1990, caracterizada pela introdução "insensata" e "acelerada" da motocicleta no cotidiano das cidades. Porém, diferentemente da primeira fase, os grupos que agora foram apoiados pelo poder público têm renda inferior aos grupos anteriores, dividindo-se entre a classe média e de baixa renda (VASCONCELLOS, 2016).

Os custos sociais da motorização no Brasil, cuja gênese é a dependência ao automóvel e a proliferação de motocicletas, não têm sido tratados com seriedade. Ao contrário, os esforços e ações do estado continuam sendo voltadas para a implantação de políticas urbanas orientadas pelo e para o uso do automóvel e da motocicleta que relegam a segundo plano as políticas de transporte público coletivo e reduze a quase zero a implementação de políticas para o transporte não motorizado. 


\section{AMAZÔNIA LEGAL: RODOVIARISMO, TRANSPORTE MOTORIZADO, VÍTIMAS DE ACIDENTES DE TRANSPORTE}

\section{Configuração da motorização na Amazônia Legal}

Os estudos realizados pelo Observatório das Metrópoles (2012-2015) utilizando dados do DENATRAN, mostraram que a região norte (que compõe maior parte dos estados da Amazônia Legal) apresentou, em 2012, a menor taxa de motorização em relação às outras regiões do Brasil, com 1,0 veículos para cada 10 habitantes. Mas, no período de 2001 a 2014, dentre todas as regiões, o maior crescimento percentual aconteceu nesta região, que passou de pouco mais de 562 mil automóveis para mais de 1,9 milhão, representando um crescimento de 238,7\% (Observatório das metrópoles, 2015). A motorização na região norte ainda é baixa, mas é a que apresenta o maior crescimento dentre todas as regiões do Brasil. A composição da frota circulante da AL é bastante semelhante às demais regiões, com o predomínio dos veículos motorizados individuais, como aponta o gráfico da figura 2, por estado.

Figura 2 - Gráfico da taxa de motorização por 10 habitantes nos estados da Amazônia Legal (2013)

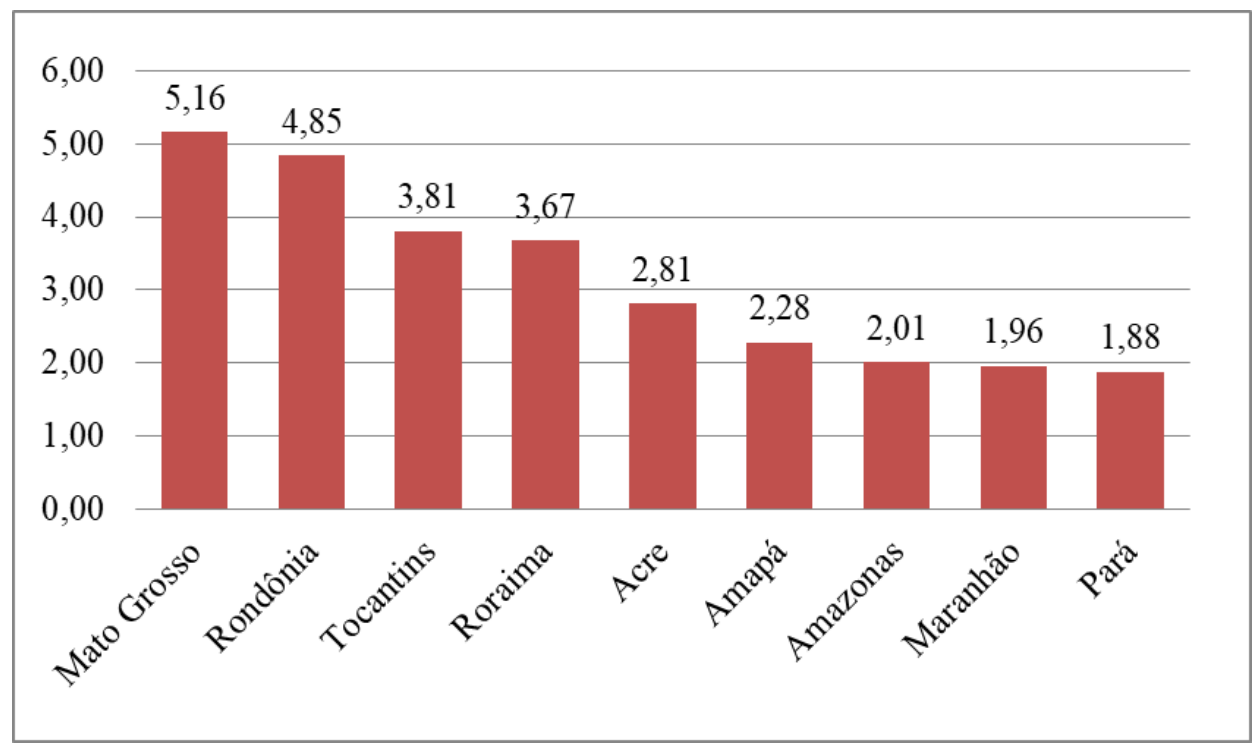

Fonte: DENATRAN, 2013

Nota-se que o estado do Mato Grosso é o que possui maior taxa de motorização, com 5,16 veículos para cada 10 habitantes, ou seja, a cada dois habitantes, um possui veículo. A segunda maior taxa, é registrada pelo estado de Rondônia, com 4,85, seguida de Tocantins com 3,81 e Roraima com 3,67. Os menores índices estão nos estados do Amazonas, Maranhão e Pará, respectivamente com 2,01; 1,96 e 1,88 veículos por 10 habitantes. A figura 3 apresenta a composição da frota de veículos da região.

Em 2013, cerca de 48\% da frota era composta por motocicletas. Em seguida aparecem os automóveis, com 33\%. Os demais veículos representavam apenas 19\%. O Mapa da figura 4 dá destaque na participação das motocicletas na composição da frota de veículos por estados. 
Figura 3 - Gráfico da composição da frota de veículos na Amazônia Legal (2013)

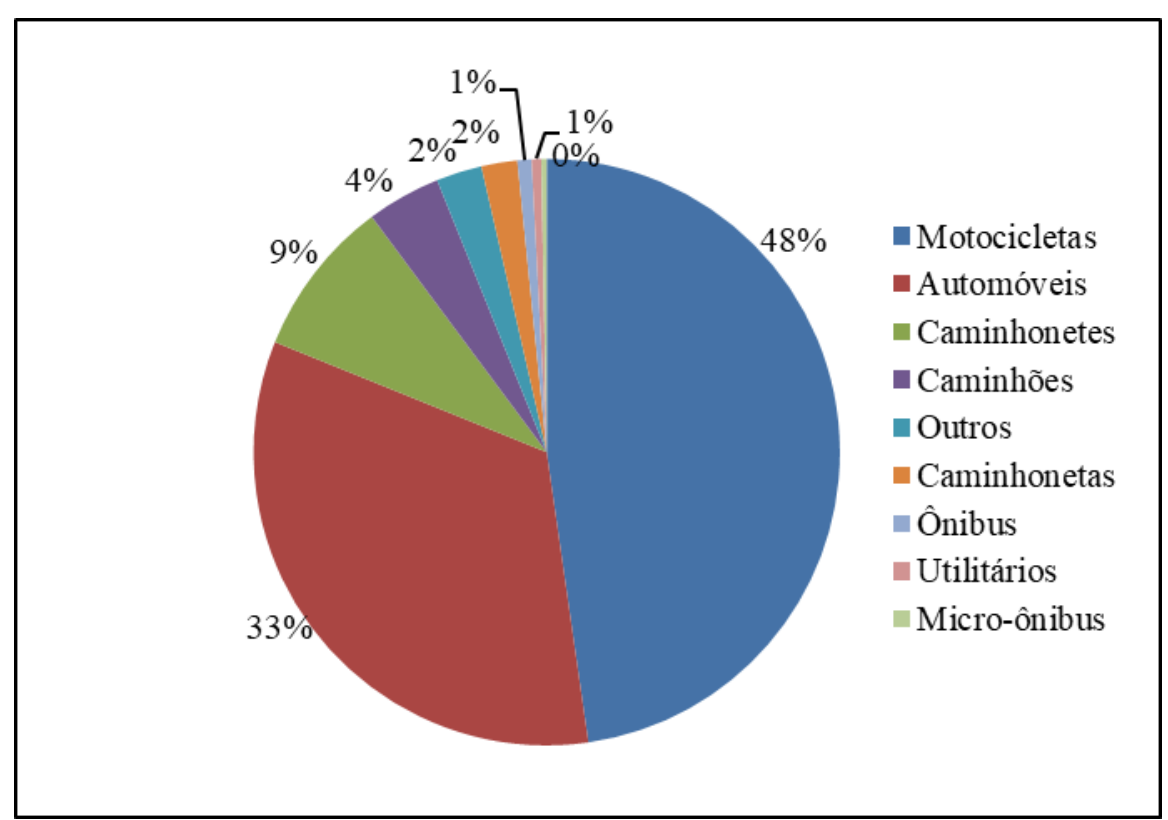

Fonte: DENATRAN, 2013. Nota: para este gráfico a frota de motonetas foi somada à de motocicletas.

Figura 4 - Amazônia Legal - Percentual de automóveis e motos na frota de veículos, 2013. [Por estado]

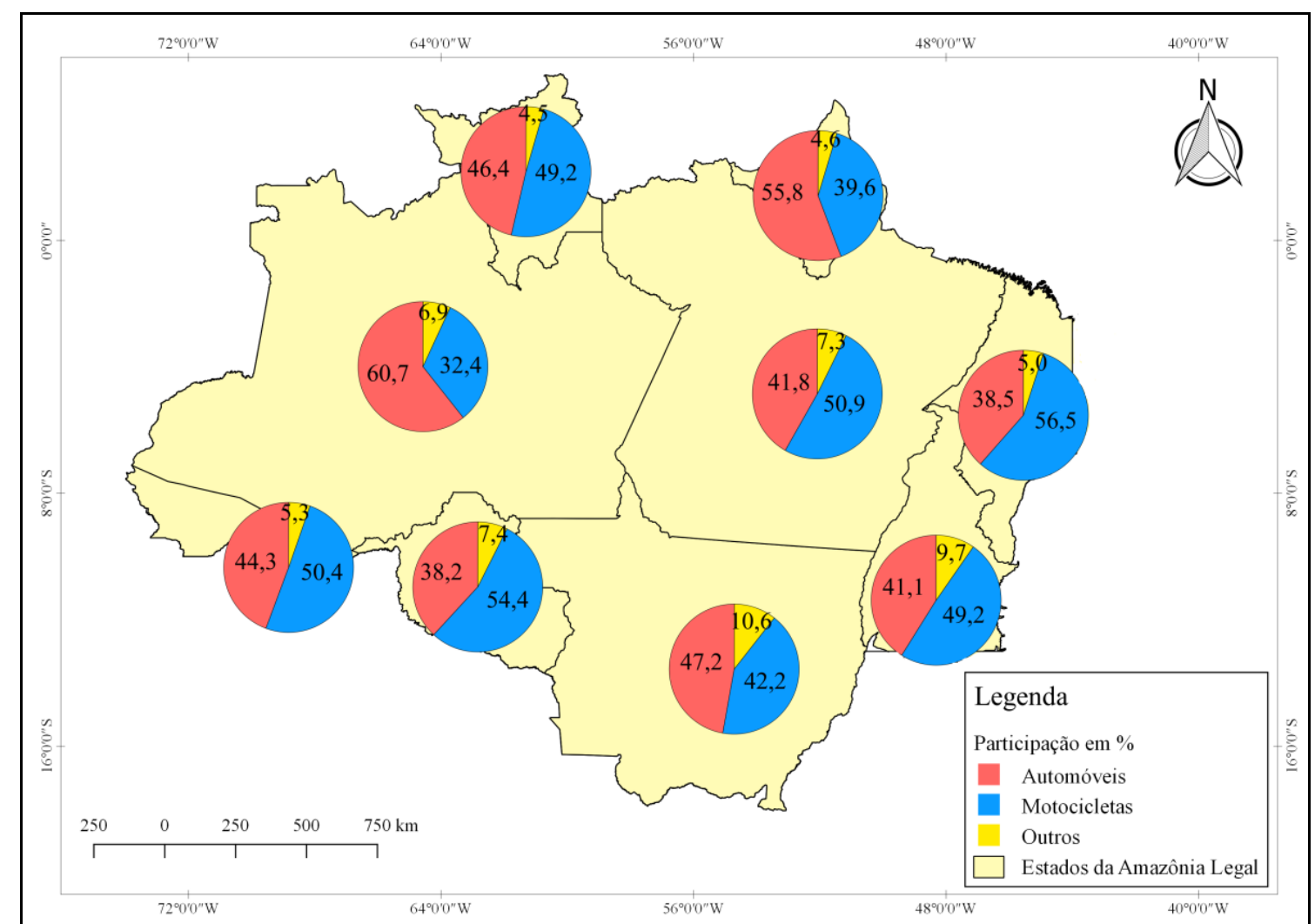

Fonte: DENATRAN,2013. Nota: para este gráfico a frota de motonetas foi somada à de motocicletas, enquanto caminhonete, caminhoneta e utilitários na categoria automóvel. 
Como é possível notar na figura 4, as motocicletas têm maior participação em seis estados: Maranhão $(56,5 \%)$, Rondônia $(54,4 \%)$, Pará $(50,9 \%)$, Acre $(50,4)$, Roraima $(49,2 \%)$ e Tocantins $(49,2 \%)$. Já nos estados do Amazonas, Amapá e Mato Grosso a maior participação é de automóveis, com $60,7 \% ; 55,8 \%$ e $47,2 \%$, respectivamente. Considerando os estados da borda leste e sul da AL, o Mato Grosso é o estado o com maior percentual de automóveis. A tabela 3 destaca a motorização individual, separada entre automóveis e motocicleta, por estados da AL em 2013.

Tabela 3 - Amazônia Legal - Taxa de motorização individual por estado em 2013

\begin{tabular}{lcc}
\hline & Veículos por $\mathbf{1 0}$ habitantes \\
\hline \multicolumn{1}{c}{ Estado } & Motocicleta & Automóvel \\
\hline Mato Grosso & 2,18 & 2,43 \\
Rondônia & 2,64 & 1,85 \\
Roraima & 1,80 & 1,70 \\
Tocantins & 1,88 & 1,57 \\
Acre & 1,41 & 1,27 \\
Amapá & 0,90 & 1,27 \\
Amazonas & 0,65 & 1,22 \\
Pará & 0,96 & 0,79 \\
Maranhão & 1,10 & 0,75 \\
\hline
\end{tabular}

Fonte: DENATRAN, 2013; IBGE, 2010.

Como é possível notar, seis estados da Amazônia Legal, (Roraima, Acre, Rondônia, Pará, Tocantins e Maranhão) a participação das motocicletas é maior do que a de automóveis. O Mato Grosso possui a maior taxa de automóveis, com 2,43 e Rondônia tem a maior por motocicleta, com 2,64 e a segunda por automóveis com 1,85. O menor índice de motocicleta ( 0,65 veículos por 10 habitantes) foi apresentado pelo estado do Amazonas e automóveis o Maranhão, com 0,75 . O mapa da figura 5 apresenta a taxa de motorização por município (veículos por 10 habitantes)

Figura 5 - Amazônia Legal - Taxa de Motorização dos municípios (2013)

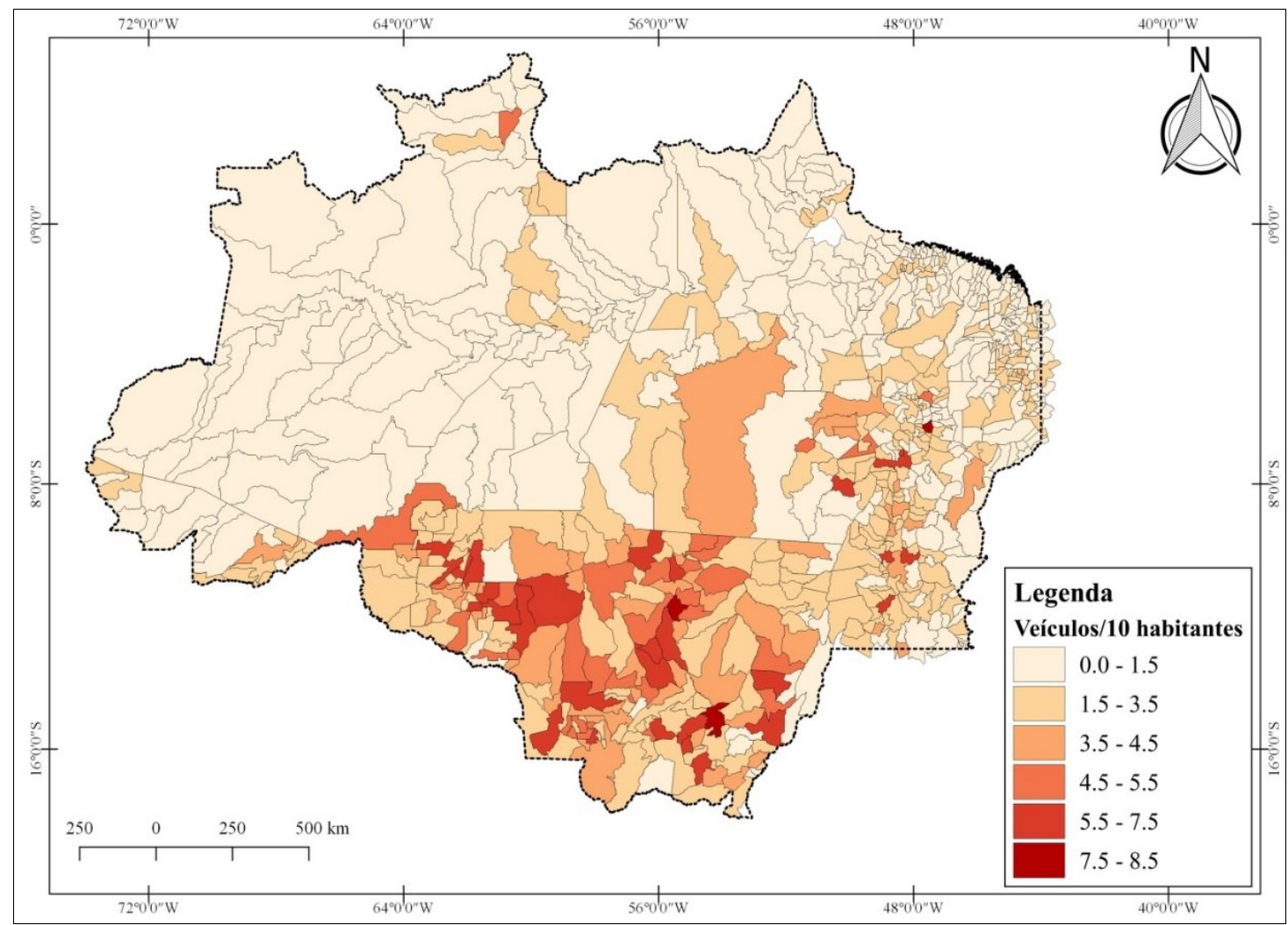

Fonte: DENATRAN, 2013; IBGE,2010. 
Como é possível observar, no nível municipal, a taxa de motorização varia de 0,0 a 8,5 veículos para cada 10 habitantes. Os municípios com maior taxa de motorização concentram-se nos estados do Mato Grosso, Rondônia e Tocantins, com motorização acima de 5 veículos por 10 habitantes. A classe mais elevada soma setenta e oito municípios, com até 8,5 , sendo esta última registrada pelo município de Tocantinópolis, no Tocantins. A sede desse município está localizada às margens do rio Tocantins e possui acesso por duas rodovias estaduais. Já as menores taxas concentram-se nos estados do Amazonas, Amapá, norte do Pará e parte central do Acre, com motorização variando de 0,0 a 1,0 . A menor taxa foi registrada no município de Afuá, localizado na ilha do Marajó, no estado do Pará, cuja taxa é de 0,0 veículos para cada 10 habitantes, pois possui uma frota de apenas 16 veículos motorizados para 35 mil habitantes. Segundo Vicente (2015), Afuá é reconhecida internacionalmente como a cidade das bicicletas, devido ao estilo alternativo de transporte e locomoção adotado pelos habitantes. Por uma questão de preservação das vias (algumas de madeira) e dos riscos oferecidos à vida dos pedestres pela motocicleta, na década de 1990 o munícipio aboliu qualquer tipo de veículo de transporte que não fosse a bicicleta. Os outros munícipios com baixa motorização são Ipixuna - AM, Chaves, Bagre e Melgaço, no Pará, e Uiramutã, em Roraima.

Com base nos dados apresentados, verifica-se que na Amazônia existe baixa motorização, principalmente nas cidades das margens dos principais rios da bacia hidrográfica. Por outro lado, nas cidades localizadas às margens de rodovias o número de veículos por habitante é maior. Pode-se, pois, dizer de uma "fronteira de motorização da Amazônia Legal", presente nos estados de Rondônia, Mato Grosso, região central do Tocantins e no sudeste do Pará.

\section{Impactos da motorização nos registros de óbitos por ATT na Amazônia Legal}

$\mathrm{Na}$ medida em que o transporte motorizado passou a ser usado em grande escala nas estradas e nas cidades, os ATT passaram a se constituir como uma das principais causas de mortalidade, tanto nos países desenvolvidos como naqueles em desenvolvimento. Na Amazônia, o aumento da mortalidade pelos usuários de motocicleta é contínuo, como mostrado no gráfico da figura 6.

Figura 6 - Evolução dos óbitos por ATT, por grupo na Amazônia Legal (1996-2013)

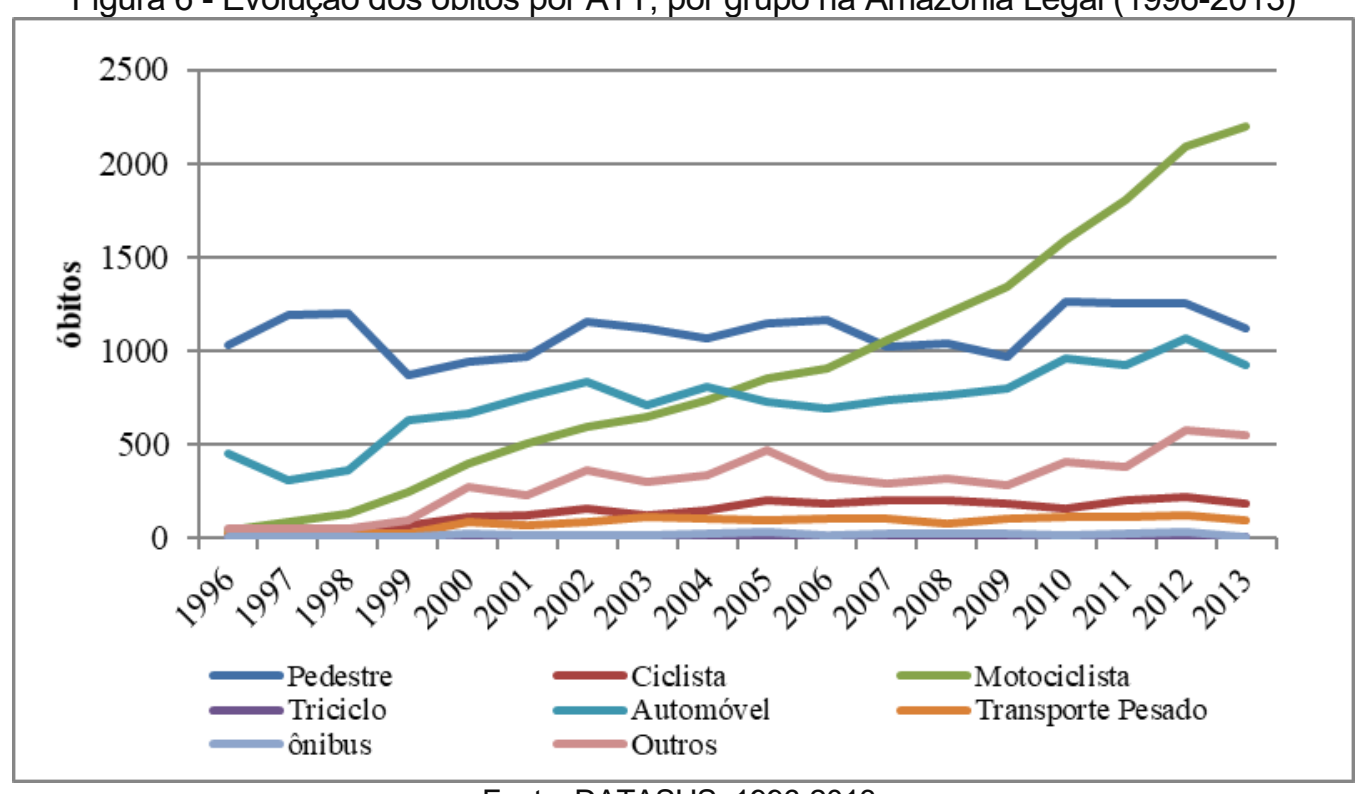

Fonte: DATASUS, 1996-2013.

Em 1996 ocorreram apenas 47 óbitos na AL envolvendo motocicletas, mas em 2013 foram 2.201. A partir de 2007 passou a ser o grupo com maior número de vítimas, se distanciando ano a ano dos demais. Os atropelamentos oscilaram entre 1.000 a 1.500, com quedas nos anos de 1999, 2009 e 2013, apesar de não ser acentuadas. Ao longo de todo o período os ocupantes de automóveis apresentam registros inferiores aos de pedestres, com queda entre 1996 e 1998 (certamente em decorrência da entrada em vigor do novo CTB em 1997) mas voltou a crescer nos anos seguintes. Com base nos dados analisados, 
verifica-se que o cenário dos óbitos na Amazônia Legal tem crescido com o passar dos anos. Assim como no restante do Brasil, os motociclistas, pedestres e ocupantes de automóveis são as maiores vítimas. O aumento da motorização da sociedade se desdobra em algumas externalidades negativas, sendo os óbitos uma das principais. A tabela 4 apresenta uma comparação da participação dos grupos de vítimas de ATT da AL com o Brasil em 1996 e 2013.

Tabela 4 - Brasil e Amazônia Legal - percentual de vítimas fatais, por condição (1996 e 2013)

\begin{tabular}{l|c|c|c|c}
\hline \multirow{2}{*}{ Grupos } & \multicolumn{2}{c|}{$\mathbf{1 9 9 6}$} & \multicolumn{2}{c}{$\mathbf{2 0 1 3}$} \\
\cline { 2 - 5 } & Brasil & Amazônia Legal & Brasil & Amazônia Legal \\
\hline Pedestres & 36,67 & 63,24 & 19,45 & 21,93 \\
Automóvel & 10,84 & 27,94 & 23,79 & 18,12 \\
Motociclista & 2,05 & 2,88 & 28,35 & 43,17 \\
Ciclista & 0,92 & 0,86 & 3,19 & 3,61 \\
Ônibus & 0,19 & 0,49 & 0,41 & 0,2 \\
Triciclo & 0,06 & 0,18 & 0,13 & 0,2 \\
Outros & 49,25 & 4,41 & 24,61 & 12,79 \\
\hline
\end{tabular}

Fonte: DATASUS, 1996 - 2013.

Em 1996 as principais vítimas de ATT na Amazônia Legal eram os pedestres, com 63,24\%, enquanto no Brasil, o grupo "outros" tem o maior percentual, com $49,25 \%$, ficando os pedestres em segundo. Infere-se que o elevado índice da categoria outros decorre da falta de rigor no cadastramento das ocorrências, fato que vem sendo corrigido ao longo dos anos. Os ocupantes de automóveis também apresentaram elevados percentuais em ambos os recortes espaciais, sendo maior na Amazônia Legal, com $27,94 \%$ e $10,84 \%$ no Brasil. Em contrapartida, os ocupantes de ônibus e motocicletas aparecem com percentual abaixo de 3\%. Como é possível notar, o quadro de vítimas de 2013 é bastante diferente do ano inicial da coleta de dados. Os motociclistas passaram a representar o maior percentual de óbitos, tanto no Brasil como na AL, com $28,35 \%$ e $43,17 \%$ respectivamente. A categoria outros, com $24,61 \%$ ocuparam a segunda posição no Brasil, enquanto na AL são os pedestres, com 21,93\%, metade do percentual apresentado pelos motociclistas.

Ao analisar os dois anos e respectivos recortes espaciais, verifica-se que: a) o ônibus é o que menos contribuiu para a geração de vítimas, com menos de $1 \%$, ou seja, oferece maior segurança aos passageiros; b) no Brasil os atropelamentos caíram de $36,6 \%$ para $19,45 \%$, e aumentou o número de óbitos de motociclistas, de $2,05 \%$ para $28,35 \%$; c) na AL, os óbitos de motociclistas apresentaram uma significativa mudança, subindo de $2,88 \%$ para $43,17 \%$; d) houve uma redução da mortalidade por atropelamentos em termos percentuais, caindo de $63,24 \%$ para $21,93 \%$ das vítimas. O mapa da figura 7 apresenta o total acumulado de óbitos por ATT na AL no período de 2009 a 2013. 
Figura 7 - Amazônia Legal - total de óbitos por ATT - período de 2009 a 2013.

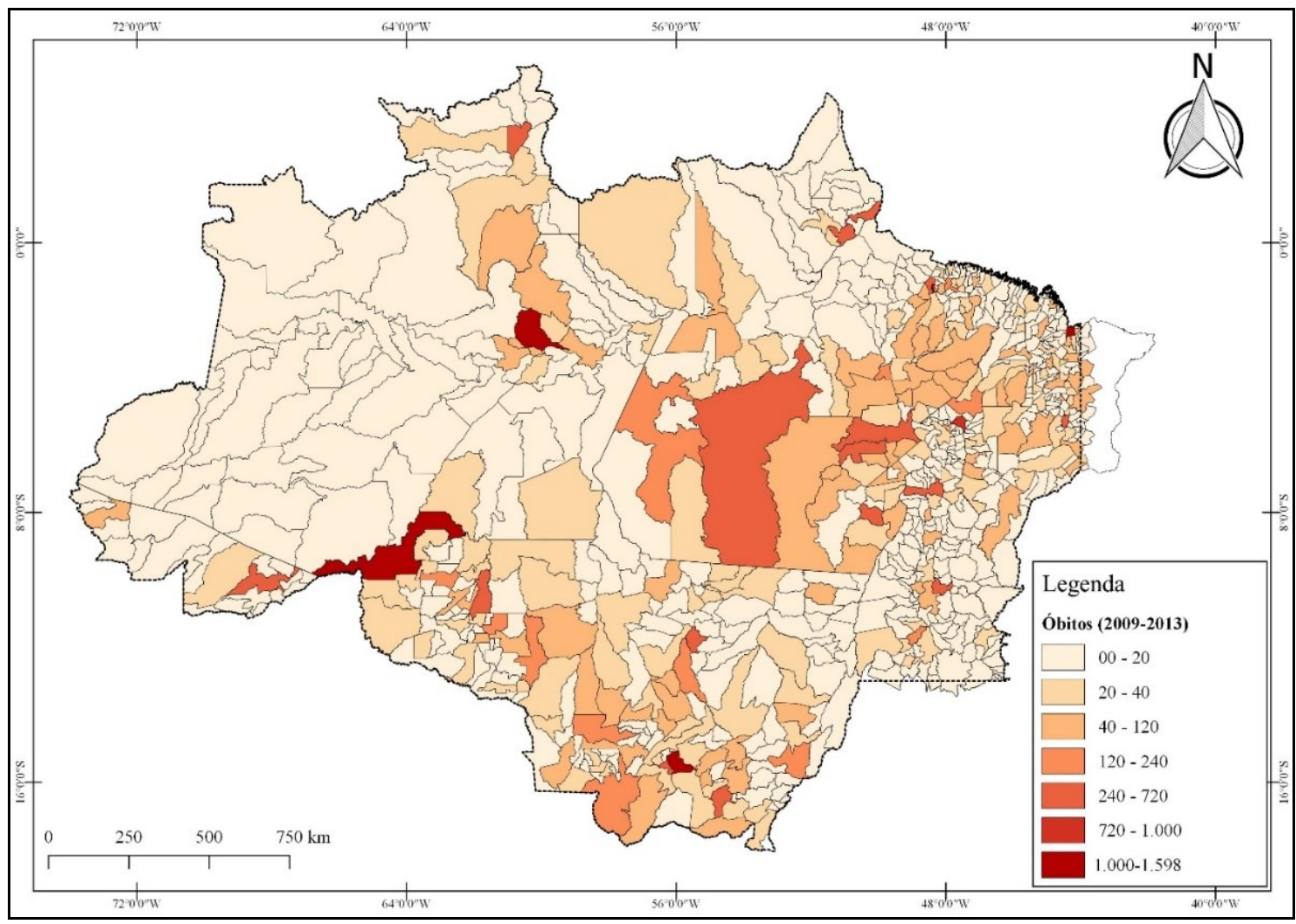

Fonte: DATASUS, 2009 - 2013. Elaborado pelo autor.

Como é possível observar, na borda leste e sul do mapa estão os municípios com os maiores índices, enquanto que nos municípios das calhas dos rios Solimões e Amazonas estão as menores ocorrências. As capitais dos estados ficaram todas em destaque. Além de possuir a maior frota municipal de veículos, também acumulam o maior número de óbitos. No nível de Estados da Amazônia Legal, dois deles demonstram muito claramente a influência dos principais eixos rodoviários na geração de óbitos por ATT e são mostrados no mosaico de figuras 8 a seguir.

O principal eixo rodoviário a - BR 364 - corta Rondônia de sudeste a noroeste e serve de ligação entre o restante do Brasil e a Amazônia ocidental, indo até o Estado do Acre, além de ser um dos principais canais de trocas de mercadorias de Roraima e Amazonas com o restante do país. Nota-se a forte influência dessa rodovia na geração de vítimas fatais causadas por ATT no estado. O Estado do Tocantins também demonstra muito claramente como os municípios com os maiores indicadores estão no entorno dos eixos rodoviários, principalmente os situados na margem da Belém-Brasília.

No Tocantins é dado destaque para vinte oito municípios com o menor (em verde) e maior (laranja), número de óbitos do estado; ambos relacionados com tipo de acesso à sede municipal. O mapa aponta que os municípios que apresentaram a maior quantidade de vítimas estão localizados na parte mais central do estado, em sua maioria às margens da BR-153, próximos de Palmas e outros mais ao sul. No total são oito municípios com acesso por rodovia federal e seis por rodovias estaduais. Já aqueles com menos óbitos localizam-se em sua maioria distantes da BR-153, e na parte leste do estado. 
Figura 8 -Tocantins e Rondônia - Total de óbitos por ATT e municípios com maior e menor número destes. [Período de 2009 a 2013]
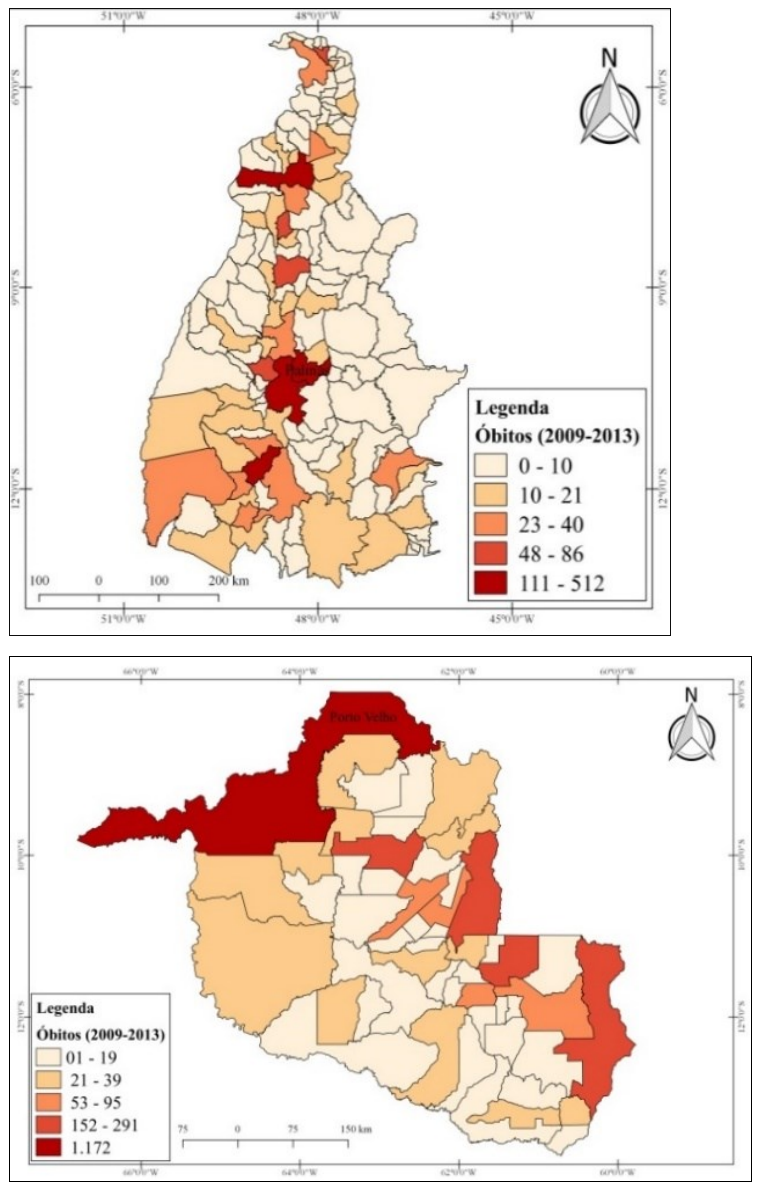
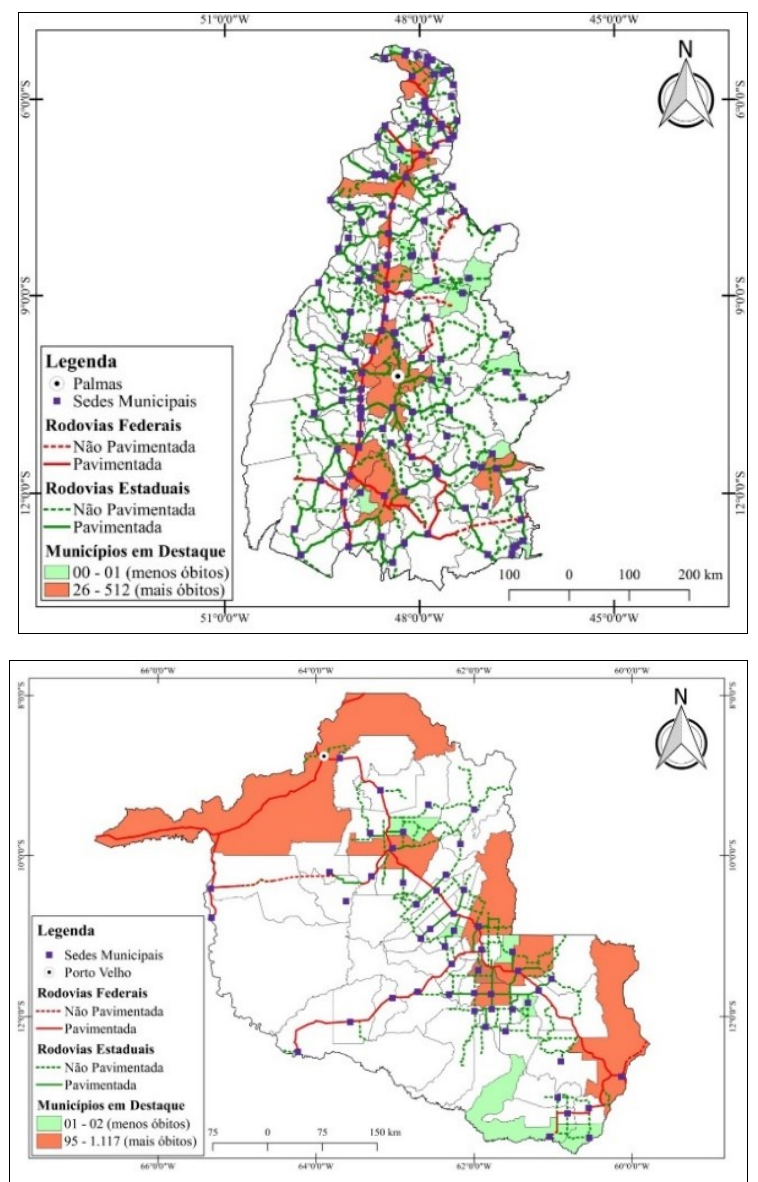

Fonte: DATASUS, 2009 - 2013. Elaborados pelo autor.

Em Rondônia, dos municípios que apresentaram maior número de vítimas, cinco deles estão localizados às margens da principal rodovia do estado - a BR-364, e Rolim de Moura no entroncamento de duas rodovias estaduais - a RO 479 e RO 010. Dentre os municípios com o menor número de vítimas, quatro possuem acesso por rodovias estaduais e dois têm acesso precário (rodovia não pavimentada) - Cabixi e Pimenteiras do Oeste, ambos localizados no extremo sudoeste do estado.

Com base nos dados analisados, verifica-se que o cenário dos óbitos na AL tem crescido com o passar dos anos. Assim como no Brasil, os motociclistas, pedestres e ocupantes de automóveis são as maiores vítimas do trânsito. Isto aponta a realidade de uma Amazônica inserida num contexto brasileiro, em que o aumento da motorização, sobretudo por motocicletas, se desdobra em algumas externalidades negativas, sendo os óbitos o principal deles. No contexto regional, considerando as particularidades da AL notou-se que existe relação da motorização e geração de vítimas com a presença eixos rodoviários, especialmente as federias que conectam os estados da borda leste-sul, como Maranhão, Tocantins, Mato Grosso e Rondônia com o restante do Brasil.

\section{CONSIDERAÇÕES FINAIS}

Como foi possível notar dos 772 municípios da Amazônia Legal, cerca de 30, 95\% (239) tem baixa ou inexistente conectividade rodoviária com o restante do país, fator que influencia fortemente na geração de óbitos por acidentes de transportes. Na parte da região com elevado padrão rodoviário a taxa de geração de óbitos acompanha a de motorização.

As políticas adotadas pelo Brasil têm priorizados os modos rodoviários motorizados de transporte, claramente voltadas para a valorização dos automóveis e motocicletas. Considerando os dados 
analisados neste trabalho, verifica-se que na Amazônia Legal há maior predominância de motocicletas. São fatores que contribuem para esta realidade: a) incentivos governamentais para aquisição e uso desses veículos; b) $O$ fato de que boa parte das cidades da Amazônia Legal são de pequeno e médio porte e não contam com transporte público coletivo por ônibus; c) Facilidade de uso da motocicleta estradas vicinais e trilhas e; d) A falta de estadas e o baixo padrão de renda de parte da população dificulta a aquisição, manutenção e uso do automóvel na região. Reflexo desse padrão de motorização é o aumento do número de mortes dos usuários de motocicletas, maior que pedestres e ocupantes de automóveis.

Como os dados puderam mostrar, apesar da promulgação de leis, tais como o novo CTB, as mortes vêm aumentando na região. Assim, é de se esperar que o crescimento da frota de veículos mantenha o acelerado ritmo dos anos recentes e que a geração de vítimas fatais também acompanhe este crescimento.

\section{AGRADECIMENTO}

À Fundação de Amparo à Pesquisa do Estado do Amazonas - FAPEAM pela concessão da bolsa de pesquisa.

\section{REFERÊNCIAS}

ABRACICLO. Associação Brasileira dos Fabricantes de Motocicletas, Ciclomotores, Motonetas, Bicicletas e Similares. Anuário de Produção de Motocicletas de 1975 a 2015. São Paulo, 2015.

ANFAVEA. Associação Nacional das Empresas Financeiras de Montadoras. Anuário estatístico da indústria automotiva brasileira. São Paulo, 2016.

ANFAVEA. Associação Nacional das Empresas Financeiras de Montadoras. Indústria Automobilística Nacional Brasileira - $\mathbf{5 0}$ anos. São Paulo, 2006.

CAPUTO, A. C. e MELO, H. P. A industrialização brasileira nos anos de 1950: uma análise da instrução 113 da SUMOC. Estudos Econômicos São Paulo, v. 39, n. 3, p. 514-538. 2009. https://doi.org/10.1590/S0101-41612009000300003

DATASUS (1996-2013) - Departamento de Informações do Sistema Único de Saúde. Informações de Saúde. MS/SVS/CGIAE Sistema de Informações sobre Mortalidade - SIM. Disponível em: http://tabnet.datasus.gov.br/ Acesso em: 18 de junho de 2018.

DENATRAN (2001 - 2015) - Departamento Nacional de Trânsito. Frota de Veículos do RENAVAM. Disponível em http://www.denatran.gov.br/estatistica/237-frota-veiculos Acesso em: 18 de junho de 2018.

IBGE Instituto Brasileiro de Geografia e Estatística. Censo Demográfico, 2010. Rio de Janeiro. Disponível em: http://downloads.ibge.gov.br/downloads_estatisticas.htm. Acesso em: 19 de junho de 2018.

IPEA - Instituto de Pesquisa e Economia Aplicada. Mobilidade Urbana: O automóvel ainda é prioridade. Revista de Informações e Debate. Ano 8, ed. 67, 2011. Disponível em: https://www.ipea.gov.br/desafios/index.php?option=com_content\&view=article\&id=2578:catid=28\&lte mid=23 Acesso em: 20 de julho de 2018.

LATINI, S. A A implantação da Indústria Automobilística no Brasil: da substituição de importações ativa à globalização passiva. São Paulo: Alaúde Editorial, 2007.

LEITE, A. D; CAMILO, Ellen A.; SCHOR, T. Barco, moto e bicicleta: deslocamentos intraurbanos nas cidades de Itacoatiara e Parintins. SCHOR, T e SANTANA, P. V. Dinâmica urbana na Amazônia Brasileira. Vol. 2. Manaus: Valer, 2015.

OBSERVATÓRIO DAS METRÓPOLES (2015) Estado da Motorização Individual no Brasil: relatório 2015. Instituto de Pesquisa e Planejamento Urbano e Regional - IPPUR. Disponível em: http://www.observatoriodasmetropoles.net/download/automoveis_e_motos2015.pdf Acesso em: 20 de julho de 2018.

VASCONCELLOS, E. A. Mobilidade urbana e cidadania. Rio de Janeiro: SENAC,2012. 
Políticas de Transporte no Brasil: a construção de uma mobilidade excludente. Barueri: Manole, 2013.

; CARVALHO, C.H.R.; PEREIRA, R. H. M (2011) Transporte e Mobilidade Urbana. Brasília, DF: Comissão Econômica para a América Latina e o Caribe - CEPAL. Escritório no Brasil/ IPEA.

MENDONÇA, A. Política Nacional de Transporte Público no Brasil: organização e implantação de corredores de ônibus. Revista de Transporte Público-ANTP. V. 33, p.73-95 2010.

VICENTE, M Afuá, a Veneza Marajoara, é a cidade das bicicletas na Amazônia. Disponível em: https://www.greenme.com.br/viajar/1556-afua-a-veneza-marajoara-e-a-cidade-das-bicicletas-naamazonia Acesso em: 10 de agosto de 2018.

WHO - World Health Organization - Global status report on road safety 2015. Geneva, Disponível em: https://www.who.int/violence_injury_prevention/road_safety_status/2015/en/ Acesso em: 10 de junho de 2018.

Recebido em: 20/09/2020

Aceito para publicação em: 20/11/2020 